\title{
Health risks of exposure to CS gas (tear gas): an update for healthcare practitioners in Hong Kong
}

\author{
Anderson CO Tsang ${ }^{1}$ *, MB, BS, LF Liं ${ }^{2}$ MB, BS, Raymond KY Tsang ${ }^{3}$, MB, ChB, MS \\ ${ }^{1}$ Division of Neurosurgery, Department of Surgery, The University of Hong Kong, Pokfulam, Hong Kong \\ ${ }^{2}$ Department of Neurosurgery, Queen Mary Hospital, Pokfulam, Hong Kong \\ ${ }^{3}$ Division of Otorhinolaryngology, Department of Surgery, The University of Hong Kong, Pokfulam, Hong Kong
}

Hong Kong Med J 2020;26:151-3

*Corresponding author: acotsang@hku.hk

https://doi.org/10.12809/hkmj198145

The recent social unrest in Hong Kong, brought about by the controversial amendments to the Fugitive Offenders Ordinance (Cap. 503), has put the crowd control actions of the Hong Kong Police Force in the limelight. In 2019, Hong Kong witnessed the most extensive civilian protests since the 1960s, and consequently the police have used crowd control measures to restore social order. ${ }^{1}$ In particular, ochlorobenzylidene malononitrile, also known as CS gas or simply tear gas, is deployed during crowd dispersal operations. At the time of writing, over 1800 canisters of CS gas have been used in Hong Kong since June 2019, often in high concentrations in densely populated commercial or residential areas or poorly ventilated areas. This has led to CS gas exposure among not only protestors, but also news reporters, bystanders, and residents and employees in nearby buildings.

To better inform local medical practitioners, we present a brief literature review of the clinical effects and risks related to CS gas exposure.

\section{Chemical properties}

The CS gas, named after Corson and Stoughton who first synthesised it in 1928, is the most commonly used crowd control agent worldwide and can be dispersed as a fine powder, a jet of solution, or as aerosols by pyrotechnic generation. ${ }^{2}$ It acts as an SN2-alkylating agent at nucleophilic sites in the pyruvate decarboxylase system. This causes bradykinin release resulting in pain sensation, as well as stimulates the pulmonary irritant receptors causing bronchoconstriction. It is also a potent TrpA1 receptor agonist, which has high concentration in trigeminal neurons, and is responsible for lacrimation effect via activation of the tearing reflex. Upon contact with moisture on skin or mucosal surface, the chlorine atoms released from CS gas is reduced to hydrochloride acid, causing burns and mucosal irritation. The CS gas degrades by hydrolysis in water, with a short half-life of 15 minutes at room temperature. The half-life is shortened to 1 minute in alkaline solution. $^{2}$

\section{Clinical effects}

Most clinical effects secondary to CS gas exposure are acute and transient. These include ocular effects: lacrimation, blepharospasm, eye irritation, conjunctivitis and periorbital oedema, which typically onset within minutes and resolves in 1 day. ${ }^{3}$ Respiratory manifestations can occur immediately such as cough, dyspnoea, haemoptysis, bronchoconstriction and laryngospasm; or after a latency period of up to 1 to 2 weeks causing hypersensitivity pneumonitis or reactive airways dysfunction syndrome. Compared with unexposed controls, patients exposed to CS gas demonstrate sustained worse lung function in terms of the proportion of forced expired volume in first second to forced vital capacity, and the maximum midexpiratory flow rate, especially if they are smokers. ${ }^{4}$ Gastrointestinal symptoms including diarrhoea, vomiting, haematemesis, and abdominal pain have also been attributed to CS gas exposure or ingestion. ${ }^{5}$ Perhaps less appreciated are the dermatological effects of CS, which ranged from mild erythema to extensive blistering and burn. These can have variable latency period from minutes to 2 weeks. Burn was the most common symptom observed during the last large-scale deployment of CS gas in Hong Kong in 1995, in which over 1500 canisters of CS were used. In that incident in a refugee detention centre, $52 \%$ of the affected detainees aged $<1$ to 51 years had acute burns affecting on average 3\% total body surface area. ${ }^{6}$ While most burns were superficial, 22 patients had deep partial thickness burn, two of which were children and required burn unit admission. Long-term complications occurred in eight patients in the form of hypergranulation tissue or hypertrophic scars. Of note, the mechanism of burn can be caused by flames arising from explosion of tear gas grenades, contact burns from hot canisters, and chemical burns from contact with CS powder. ${ }^{7}$ These health risks to the public have led to members of the scientific community to call for restraint in the use of these crowd control chemicals. $^{8}$ 


\section{Fatal cases}

Because of the high lethal-dose to effective-dose ratio, CS gas is considered a less-than-lethal weapon. However, mortalities have been attributed to CS gas exposure secondary to respiratory effects, including a case of respiratory arrest in Bahrain, ${ }^{3}$ and a case of acute necrotising laryngotracheobronchitis in the United States. ${ }^{9}$ Importantly, these mortalities were related to CS gas use in a confined space with poor ventilation, reflecting the danger of indoor use of CS gas. Traumatic brain or cervical cord injuries caused by CS canisters or cartridges have also resulted in fatalities, including in individuals aged $<18$ years. ${ }^{3,10-13}$ In a recent case in 2018, an entire CS canister penetrated the cranium and lodged in the frontal and temporal lobe of a 27-year-old Iraqi man, leading to his death soon after hospital admission. ${ }^{13}$ These deaths and other reports of ocular and maxillofacial injuries causing blindness, upper airway compromise, and permanent disfigurement highlight the risk of close-range use of CS firearms in densely populated areas. ${ }^{14,15}$

\section{Risk to healthcare workers}

Healthcare workers can also be secondarily affected by CS gas when caring for CS-exposed patients. In two instances, unsuspecting emergency department nurses had eye, skin and respiratory irritation after being secondarily contaminated while treating CSexposed patients, necessitating decontamination of the triage area. ${ }^{16,17}$ Anaesthesiologists are another at-risk group, with reports of secondary CS gas exposure during endotracheal intubation, extubation, and nasogastric tube insertion for affected patients. ${ }^{18-20}$ Although none of these resulted in permanent damage, local healthcare professionals in Hong Kong must be aware of this occupational hazard and equip themselves with appropriate protective equipment when treating these patients. Emergency departments should also ensure their staff is trained in decontamination and isolation of CS-exposed patients and their belongings to prevent collateral damage to other patients and personnel.

\section{Conclusion}

Exposure to CS gas carries substantial risk to civilians and the healthcare professionals treating them. Although most clinical manifestations related to CS gas are acute and transient, more severe burns or, rarely, fatal incidents have occurred when CS gas is deployed, especially in poorly ventilated spaces. We urge law enforcement personnel to exercise extreme restraint and discretion when using CS gas and other crowd control methods. Local practitioners should be aware of the clinical effects and risks of CS gas in order to better treat and counsel affected patients.

\section{Author contributions}

Concept or design: All authors.

Acquisition of data: ACO Tsang.

Analysis or interpretation of data: ACO Tsang.

Drafting of the manuscript: All authors.

Critical revision of the manuscript for important intellectual content: All authors.

All authors had full access to the data, contributed to the study, approved the final version for publication, and take responsibility for its accuracy and integrity.

\section{Conflicts of interest}

The authors declare no conflict of interest.

\section{Funding/support}

This commentary received no specific grant from any funding agency in the public, commercial, or not-for-profit sectors.

\section{References}

1. Parry J. Hong Kong healthcare workers join protests. BMJ 2019;366:15027.

2. Salem H, Ballantyne B, A. Katz S. CS gas. In: Wexler P, editor. Encyclopedia of Toxicology. 1. Oxford: Elsevier; 2005: 686-90.

3. Haar RJ, Iacopino V, Ranadive N, Weiser SD, Dandu M. Health impacts of chemical irritants used for crowd control: a systematic review of the injuries and deaths caused by tear gas and pepper spray. BMC Public Health 2017;17:831.

4. Arbak P, Başer I, Kumbasar ÖO, Ülger F, Kılıçaslan Z, Evyapan F. Long term effects of tear gases on respiratory system: analysis of 93 cases. ScientificWorldJournal 2014;2014:963638.

5. Dimitroglou Y, Rachiotis G, Hadjichristodoulou C. Exposure to the riot control agent $\mathrm{CS}$ and potential health effects: a systematic review of the evidence. Int J Environ Res Public Health 2015;12:1397-411.

6. Anderson PJ, Lau GS, Taylor WR, Critchley JA. Acute effects of the potent lacrimator o-chlorobenzylidene malononitrile (CS) tear gas. Hum Exp Toxicol 1996;15:4615.

7. Zekri AM, King WW, Yeung R, Taylor WR. Acute mass burns caused by o-chlorobenzylidene malononitrile (CS) tear gas. Burns 1995;21:586-9.

8. Kaszeta D. Restrict use of riot-control chemicals. Nature 2019;573:27-9.

9. Toprak S, Ersoy G, Hart J, Clevestig P. The pathology of lethal exposure to the Riot Control Agents: towards a forensics-based methodology for determining misuse. J Forensic Leg Med 2015;29:36-42.

10. Ramu M. Death due to a tear gas shell: report of a case. J Forensic Sci 1967;12:383-5.

11. Wani AA, Zargar J, Ramzan AU, et al. Head injury caused by tear gas cartridge in teenage population. Pediatr Neurosurg 2010;46:25-8.

12. Clarot F, Vaz E, Papin F, Clin B, Vicomte C, Proust B. Lethal head injury due to tear-gas cartridge gunshots. Forensic Sci Int 2003;137:45-51.

13. Alhillo HT, Arnaout MM, Radhi HS, Al-Dhahir MA, Moscote-Salazar LR, Hoz SS. Direct head injury caused by a tear gas cartridge. Questions on safety: A case report 
from Iraq and review of the literature. J Clin Neurosci 2018;56:179-82.

14. Çorbacıoğlu ŞK, Güler S, Er E, Seviner M, Aslan Ş, Aksel G. Rare and severe maxillofacial injury due to tear gas capsules: report of three cases. J Forensic Sci 2016;61:5514.

15. Sharma AK, Shah DN, Shrestha JK, Thapa M, Shrestha GS. Ocular injuries in the people's uprising of April 2006 in Kathmandu, Nepal. Nepal J Ophthalmol 2014;6:71-9.

16. Horton DK, Burgess P, Rossiter S, Kaye WE. Secondary contamination of emergency department personnel from o-chlorobenzylidene malononitrile exposure, 2002. Ann
Emerg Med 2005;45:655-8.

17. Horton DK, Berkowitz Z, Kaye WE. Secondary contamination of ED personnel from hazardous materials events, 1995-2001. Am J Emerg Med 2003;21:199-204.

18. Barlow N. Precautions should be taken before anaesthetising anybody, who has been exposed to CS gas to prevent complications such as this making intubation impossible. Resuscitation 2000;47:92.

19. Davey A, Moppett IK. Postoperative complications after CS spray exposure. Anaesthesia 2004;59:1219-20.

20. Bhattacharya ST, Hayward AW. CS gas-implications for the anaesthetist. Anaesthesia 1993;48:896-7.

\section{Answers to CME Programme Hong Kong Medical Journal February 2020 issue}

Hong Kong Med J 2020;26:10-8

I. Second tier non-invasive prenatal testing in a regional prenatal diagnosis service unit: a retrospective analysis and literature review
A
1. True
2. False
3. False
4. True
5. True
B
1. False
2. True
3. True
4. True
5. False

Hong Kong Med J 2020;26:19-26

II. Age, sex, and disease status as determinants of skin hydration and transepidermal water loss among children with and without eczema
A
1. False
2. False
3. False
4. False
5. True
B
1. False
2. False
3. False
4. True
5. False 